\section{$\overline{\substack{\text { hommes } \\ \text { \& migrations }}}$}

\section{Hommes \& migrations}

Revue française de référence sur les dynamiques

migratoires

1333 | 2021

L'enfance en exil

\title{
Moustafa Mohammad-Deeb, Une enfance syrienne d'Idlib à Oléron
}

Illustrations Agathe Zimmer, Dolus-d'Oléron, éd. ComCiPMO (Comité citoyen pour l'accueil des réfugiés en Pays Marennes Oléron), 2020, $5 €$.

\section{Mustapha Harzoune}

\section{(2) OpenEdition}

1 Journals

\section{Édition électronique}

URL : https://journals.openedition.org/hommesmigrations/12785

DOI : 10.4000/hommesmigrations. 12785

ISSN : 2262-3353

Éditeur

Musée national de l'histoire de l'immigration

Édition imprimée

Date de publication : 1 avril 2021

Pagination : 226

ISBN : 978-2-919040-55-1

ISSN : 1142-852X

Référence électronique

Mustapha Harzoune, " Moustafa Mohammad-Deeb, Une enfance syrienne d'Illib à Oléron », Hommes \& migrations [En ligne], 1333 | 2021, mis en ligne le 01 avril 2021, consulté le 26 juillet 2021. URL : http:// journals.openedition.org/hommesmigrations/12785; DOI : https://doi.org/10.4000/ hommesmigrations. 12785 


\section{Une enfance syrienne d'Idlib à Oléron}

Moustafa Mohammad-Deeb, illustrations Agathe Zimmer, Dolus-d'Oléron, éd. ComciPMO (Comité citoyen pour l'accueil des réfugiés en Pays Marennes Oléron), 2020, $5 €$.

\section{Une enfance syrienne d'Illib à Oléron}

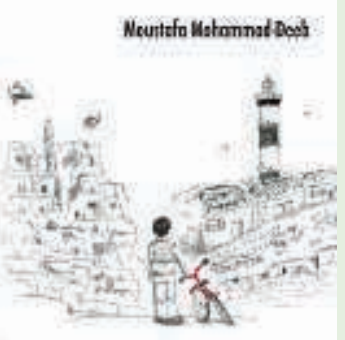

Ce court texte est celui d'un enfant, parti d'Idlib à l'âge de 6 ans avec sa famille en 2011 et qui, à 14 ans, devenu un adolescent d'Oléron, raconte, en français, le périple d'une famille syrienne, entre guerre et hospitalité. "Alors que j'avais 6 ans en 2011, mes parents étaient encore jeunes. On était heureux dans la famille, on n'avait pas de problème. On était en bonne santé, on avait des amis qui n'habitaient pas trop loin. Notre vie était tranquille, mais petit à petit elle a changé... ». En fait, tout basculera un jour de 2011, «on était à l'école» écrit-il. Le quartier est investi par la soldatesque du bourreau Assad. Dans les rues, parti se réfugier chez son grand-père, l'enfant «a peur». Tout n'est que bruit et agitation: «armée», «tanks», «militaires», «soldats». Les maisons sont fouillées, pillées, détruites et, bientôt, bombardées. C'est d'ailleurs un bombardement qui détruira la maison familiale. Moustafa sortira indemne des décombres, avec, pourtant, un mal de dos, un mal de dos qui persiste toujours. La violence s'abattra sur les hommes, les femmes, les enfants. Dans l'horreur, les fameux Moukhabarat, les services de renseignement du régime, ne seront pas les moins cruels.

Mohammad, son père, est alors travailleur immigré au Liban. Il revient au pays pour emmener Zaïnab, son épouse, et leurs quatre enfants. Le «11/11/2011», la famille Deeb entre au Liban. Avec ses mots d'enfants, Moustafa raconte les premiers mois de l'exil, dans un garage, en plein hiver; l'école où il apprendra le français «parce que les écoles arabes du Liban ne voulaient pas de nous», puis il y aura l'accueil de l'UNHCR. Moustafa partagera alors le quotidien d'autres réfugiés: "On n'était plus mélangé avec les enfants libanais, ce qui m'arrangeait bien!» écrit le gamin. Il faut dire que l'hospitalité et la solidarité ne se mesurent pas forcément à la proximité et que, pour parler une même langue, on n'en est pas moins différents, voire hostiles (reste que le Liban accueille entre 1 et 1,5 million de réfugiés syriens).

C'est en exil que la famille apprend la mort d'un oncle paternel. Il faisait la queue pour acheter du pain quand l'aviation a déversé ses bombes sur les civils syriens. En 2016 - sept ans après leur entrée au Liban! -, la famille est informée qu'elle va être accueillie en France. Accueil, installation, amitiés, langue française... pour Moustafa, «la vie à Oléron est agréable et on a envie qu'elle dure car on va sans doute rester en France longtemps, vu l'état de la Syrie...»

"On est bien en France, On y a de vrais amis» écrit Moustafa et, pourtant, la famille, les amis restés au pays manquent. Pire, «ils vont mal et nous avons honte d'être ici». La culpabilité de l'exil chez un enfant de 14 ans! Comme dit l'écrivain Saïd Mohamed en postface, «paix à vous».

À propos du ComCiPMO: il a été créé par des hommes et des femmes qui, las de s'indigner et de pétitionner, ont décidé d'aller plus loin, de s'organiser pour accueillir des réfugiés. En 2017, trois familles syriennes sont annoncées, dont la famille Deeb. En 2020, six familles syriennes vivent désormais sur l'île. Une préface, sensible et avertie, revient brièvement sur ces années où «un monde nouveau» s'est ouvert. Loin (à l'abri peut-être) des plateaux télévisés et des fanfaronnades de tribunes. M. H. 